\title{
A NEW APPLICATION OF CONVEX SEQUENCES
}

\author{
HÜSEYIN BOR
}

Abstract. In this paper, an application of convex sequences dealing with $|C, \alpha|$ summability has been generalized to the $|C, \alpha, \beta ; \delta|_{k}$ summability. Some new results have also been obtained. Mathematics subject classification (2010): 40D15, 40F05, 40G05, 40G99.

Keywords and phrases: Cesàro mean, infinite series, summability factors, convex sequences.

\section{REFERENCES}

[1] H. BoR, On a new application of power increasing sequences, Proc. Estonian Acad. Sci. Phys. Math. 57 (2008), 205-209.

[2] H. Bor, On the generalized absolute Cesàro summability, Pac. J. Appl. Math. 2 (2009), 35-40.

[3] D. BorweIn, Theorems on some methods of summability, Quart. J. Math., Oxford Ser. 9 (1958), 310 316.

[4] H. C. CHOw, On the summability factors of Fourier Series, J. London Math. Soc. 16 (1941), 215-220.

[5] G. DAS, A Tauberian theorem for absolute summability, Proc. Camb. Phil. Soc. 67 (1970), 321-326.

[6] T. M. FLETT, On an extension of absolute summability and some theorems of Littlewood and Paley, Proc. London Math. Soc. 7 (1957), 113-141.

[7] T. M. FLETT, Some more theorems concerning the absolute summability of Fourier series and power series, Proc. London Math. Soc. 7 (1958), 357-387.

[8] T. PATI, The summability factors of infinite series, Duke Math. J. 21 (1954), 271-284. 